\title{
Educação escolar indígena potiguara: uma análise estrutural e material
}

\author{
Potiguara indigenous education: a structural and \\ material analysis
}

\author{
Simone Maria Silva ${ }^{1}$ \\ Claudia Cristina do Lago Borges ${ }^{2}$
}

DOI: http://dx.doi.org/10.20435/tellus.v19i38.592

\begin{abstract}
Resumo: Sou Simone Maria da Silva, filha da terra dos potiguara da Baía da Traição, na Paraíba, da aldeia Tramataia. Realizei o sonho, como ainda poucos indígenas, de ingressar em uma universidade pública e me graduei um História. Junto com a professora Cláudia Cristina do Lago Borges, que coordena o Grupo de Estudos indígenas da Paraíba, o ABAIARA, percorremos um caminho que, em geral, só é visto pelo visitante como um lugar de "passeio" ou curiosidade, mas que guarda, na história e na vivência dessa gente, muito respeito à terra e, ao mesmo tempo, tenta manter suas identidades culturais, apesar das interferências e imposições do "homem branco". Assim, este trabalho tem como objetivo apresentar os resultados de um ano de pesquisa junto às escolas das aldeias, na qual procuramos demonstrar as peculiaridades que envolvem a realidade educacional dos indígenas Potiguara. Sabendo da importância que a escola possui para a formação de um povo, observamos como está o contingente dessas instituições nas aldeias pertencentes à cidade de Baía da Traição, visando assim, perceber como essa população está sendo atendida pela instituição escolar. Para tanto, mostraremos aqui, especificamente, o funcionamento da Escola Estadual Indígena de Ensino Fundamental e Médio Akajutibiró, bem como dos livros didáticos distribuídos nessa escola. As reflexões estabelecidas a partir da análise desses materiais nos permitem perceber como os povos indígenas estão sendo representados nesses materiais, escritos depois das mudanças estabelecidas pelas Leis que regem a educação indígena, possibilitando assim reflexões sobre as rupturas e permanências da visão tradicionalista.
\end{abstract}

Palavras-chave: educação indígena; ensino de História; livro didático.

${ }^{1}$ Abaiara - Grupos de Estudos Indígenas da Paraíba, João Pessoa, Paraíba, Brasil.

2 Universidade Federal da Paraíba (UFPB), João Pessoa, Paraíba, Brasil. 


\begin{abstract}
I am Simone Maria da Silva, daughter of the land of the Potiguara of Baía da Traição, in Paraíba, in the village of Tramataia. I realized the dream, of entering a public university and I graduated in History. Unfortunate, this feat is far away for many of my land. In University, together with my professor Cláudia Cristina do Lago Borges, who coordinates the Group of Indigenous Studies of Paraíba, ABAIARA, we walk along a path that is seen by the turist only like a place of "beautiful landscape" or curiosity, but which, have a great deal of respect for the land in the history and the experience of these native people. At the same time, they trie to maintain the cultural identities, despite the interferences and impositions of the "white man." Thus, this work aims to present the results of a year of research in the village schools, in which we will demonstrate the peculiarities that involve the educational reality of the Potiguara people. It is known the importance of the school to the formation of a people, so we observe how is the contingent of these institutions in the villages belonging to the city of Baía da Traição, in order to understand how this population is being served by the school institution. In order to do so, we will show here, specifically, the functioning of the public school Akajutibiró, as well as the textbooks distributed in this school. The reflections from the analysis of these materials allow us to understand how the indigenous peoples are represented in these materials, written after the changes established by the Laws that regulates the indigenous education. So this group of materials and data allowing make reflections on the ruptures and continuity of the traditionalist view of the indigenous.
\end{abstract}

Keywords: indigenous education; History teaching; textbook.

\title{
1 INTRODUÇÃO: UM LONGO PERCURSO RUMO À RESSIGNIFICAÇÃO EDUCACIONAL
}

Sou Simone Maria da Silva, filha da terra dos potiguara da Baía da Traição, na Paraíba, da aldeia Tramataia. Realizei o sonho, como ainda poucos indígenas, de ingressar em uma universidade pública e me graduei em História pela UFPB. Junto com a professora Cláudia Cristina do Lago Borges, que coordena o Grupo de Estudos indígenas da Paraíba, o ABAIARA, vinculado ao Departamento de História, percorremos um caminho que, em geral, só é visto pelo visitante como um lugar de "passeio" ou curiosidade, mas que guarda na história e na vivência dessa gente muito respeito à terra, e, ao mesmo tempo, tenta manter viva suas identidades culturais, apesar das interferências e imposições do "homem branco".

A ideia de conhecer sobre o sistema de ensino nas escolas da Baía da Traição surgiu em uma das reuniões do grupo, ao discutirmos sobre a educação 
indígena. Ao debatermos sobre os discursos orais, textuais, imagéticos e da própria legislação acerca da educação indígena, percebemos que muito do que vimos nas escolas não indígenas, não é distante do que se trabalha nas escolas das aldeias. Das indagações que surgiram, vimos que era necessário um estudo de campo e documental. E foi com essa inquietação que nós iniciamos um trabalho solitário e com recursos próprios, mas extremamente compensador.

Assim, este artigo apresentará alguns dos resultados de um ano de pesquisa nas escolas das aldeias da Baía da Traição, na qual procuramos identificar as peculiaridades que envolvem a realidade educacional dos indígenas Potiguara. Sabendo da importância que a escola possui para a formação de um povo, observamos como está o contingente dessas instituições nas aldeias, visando assim, perceber como essa população está sendo atendida pela instituição escolar. Para tanto, apresentaremos aqui como amostragem o funcionamento da Escola Estadual Indígena de Ensino Fundamental e Médio Akajutibiró, bem como dos livros didáticos distribuídos nessa escola. As reflexões estabelecidas a partir da análise desses materiais nos permitem perceber como os povos indígenas estão sendo representados nesses materiais, escritos depois das mudanças estabelecidas pelas Leis que regem a educação indígena, possibilitando assim reflexões sobre as rupturas e permanências da visão tradicionalista.

O principal intuito de pesquisar o tema se deu, em primeiro lugar, pelo meu vínculo familiar e identitário com os potiguara da Baía da Traição, e em segundo lugar, pela preocupação em identificarmos como a proposta de educação indígena se aplica nas escolas potiguara da Baía da Traição. Desse modo, procuramos dedicar um olhar atento na estrutura das escolas presentes nas aldeias, com o objetivo de entender como alunos e professores têm se adequado a esse modelo de ensino, e como este, que se propõe a ser diferenciado, se confronta com os modelos tradicionais do ensino implantado pelo "homem branco".

No Brasil, desde o século XVI, a educação era regulada pelos padres jesuítas através da catequização, civilização e submissão. Nesses modelos, os indígenas que viviam em aldeamentos foram obrigados a aprender a língua portuguesa, bem como os costumes e valores da sociedade colonial, ou seja, eram ensinados desde criança a "deixar de ser índios" e "aprender a ser gente". O objetivo desse sistema de ensino era implantar uma cultura civilizatória e diversificar o modo 
de vida dos povos indígenas, impondo-lhes os valores dos colonizadores, que doravante, passaremos a chamar de invasores.

No momento em que a coroa portuguesa passou a enxergar nos indígenas a mão de obra escrava da qual precisavam para aumentar a produção agrícola da colônia, o trabalho de catequese realizado pelos jesuítas tornava-se dispensável, assim, o apoio antes concedido pela coroa aos mesmos, foi revogado, e os missionários acabaram sendo expulsos do Brasil. Com a expulsão dos jesuítas em meados do século XVIII, foi implantado o regime de Diretório ${ }^{3}$, que, além de continuar com o regime de expropriação, proibia o uso das línguas indígenas nas salas de aula, ou seja, não representou nenhuma mudança significativa para essas populações, de certa forma até contribuiu para intensificar a escravização desses povos. Assim, em 1798, o Diretório foi revogado e, desde então, nada o substituiu oficialmente até que, em 1845, foi definido o Regulamento das Missões, que reintroduziria os missionários no Brasil para se responsabilizar pela civilização dos indígenas através da catequese. Desse modo, o sistema de aldeamento é retomado, no entanto esses novos missionários possuíam diferenças relevantes em relação aos jesuítas, uma delas é que não possuíam a mesma autonomia no tocante ao regimento dos indígenas, eles ficaram totalmente à serviço do governo brasileiro; um outro ponto divergente é que estes, acreditavam que o convívio dos indígenas com os cristãos seria um facilitador para a catequese.

Todavia essa convivência com os não índios acarretou no descontrole de gastos levando algumas províncias, por volta do século XIX, a não ter condições de continuar mantendo os indígenas nas escolas dos aldeamentos, e por essa razão, passaram a investir em institutos de educação e internatos, que segundo Amoroso (2001, p. 138)

[...] a presença de não-índios nos aldeamentos do século XIX fez com que, na maioria das vezes, a escola e outras instituições de apoio às populações indígenas aldeadas acabassem atendendo aos não-índios, usando para isso a verba destinada à catequese dos índios.

3 O cargo de diretor dos índios foi criado em 1757 e ficou conhecido na historiografia como Diretório dos índios, que tinha por objetivo, administrar e governar os índios. 
Nessas instituições, havia dois principais modelos de educação, que eram o assimilacionista de submissão ${ }^{4}$ e o assimilacionista de transição ${ }^{5}$; esses paradigmas eram comuns junto aos povos indígenas que mantiveram contato direto com os invasores, nesse caso, podemos citar o povo Potiguara, na Paraíba.

Desde a chegada dos invasores, o modo de vida dos Potiguara vem passando por diversas modificações, refletindo-se nos costumes, crenças e valores. Nesse processo de transformações, a língua mãe dos Potiguara, o tupi, passou a ser proibida e foi perdendo cada vez mais espaço para a língua portuguesa, de tal modo a ser esquecida e quase extinta durante um longo período da história desse povo. Essa descaracterização educativa implantada pelos invasores somente seria corrigida no século XX, por meio de ações propostas pelo Estado, associações, organizações, grupos religiosos e principalmente grupos indígenas. E a ação mais efetiva nesse processo encontra-se na Constituição de 1988, na qual os povos indígenas conquistaram o direito a uma escola específica, diferenciada, intercultural, bilíngue e de qualidade, que respeita seus costumes e seus princípios educacionais.

Entretanto a eficácia desse novo espaço educacional e cultural ainda permanece resistente, mantendo essas populações invisíveis no contexto histórico brasileiro. Essa situação só começou a ser modificada nos anos de 1996 com a implementação da Lei 9.394/96 de Diretrizes e Bases da Educação Nacional (LDBEN), que, em seu capítulo II da Seção III, no parágrafo $3^{\circ}$ do Artigo 32, determina que as comunidades indígenas, além de ter aulas regulares ministradas em língua portuguesa, também poderiam utilizar sua língua materna, bem como seus próprios processos de Ensino-aprendizagem, levando em consideração as especificidades de cada aldeia.

Outro passo importante nessa inserção dos povos indígenas na história do Brasil foi dado com a Lei 11.645/08, a qual tornou obrigatório o ensino da temática "História e Cultura Afro-Brasileira e Indígena", em todos os níveis, ciclos e modalidades de ensino. Desse modo, como afirma Padilha (2009, p.4)

4 Consistia em retirar as crianças indígenas das suas famílias e da sua convivência nas aldeias e levá-las para internatos, onde seriam catequizadas.

5 Este modelo não retirava as crianças das aldeias, implantava a escola em seu território, utilizando a língua mãe dos índios nos anos iniciais na intenção de alfabetizá-los, para então, introduzir o português gradativamente até excluir completamente a língua indígena do currículo escolar. 
[...] a realidade dos povos indígenas foi legalmente reconhecida, e por essa razão, a diversidade não deve ser vista de forma alguma como um legado a desigualdade social e sim, como um direito de ser e de viver uma identidade étnica.

Nesse sentido, o reconhecimento legal contribuiu para incentivar o respeito à diversidade cultural nas escolas.

\section{UMA QUESTÃO ESTRUTURAL}

Durante um longo período, a educação no Brasil se deu sob os moldes das escolas tradicionais, onde o ensino era voltado para a valorização da aula expositiva centrada no professor, bem como na execução de exercícios de fixação e tarefas para casa. Nesse sistema de educação, mais valia o aluno memorizar a matéria do que propriamente aprendê-la, o que ficou conhecido como sistema "decoreba". Com os Potiguara não foi diferente, eles tiveram um longo contato com esse modelo de educação, inclusive dentro das aldeias, e durante muito tempo esses povos tiveram seus modelos educacionais próprios desconsiderados.

Assim, se faz necessário compreender que existe uma distinção entre Educação Escolar Indígena e Educação indígena Diferenciada, haja vista que os povos indígenas possuem seus próprios saberes, que são transmitidos oralmente de geração em geração, em que as crianças aprendem com seus familiares a importância de se manter viva a cultura de seu povo através de seus rituais sagrados, mantendo o respeito a seus antepassados, numa relação de construção permanente, formando assim, homens e mulheres atuantes dentro de suas aldeias. A proposta da educação diferenciada é estimular a manutenção dos hábitos de subsistência, dos costumes e da língua materna, bem como, do conhecimento cultural, respeitando seus ritos comemorativos e espirituais, evitando práticas etnocêntricas nas escolas. Para tanto, é reconhecido o papel social dos anciãos enquanto conselheiros e educadores, estimulando a sua participação nessas escolas, assim, são organizadas oficinas nas quais os alunos aprendem com os mais velhos, atividades como: cultivar a terra, produzir o artesanato, pintar o

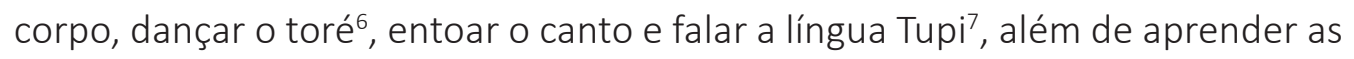
estratégias utilizadas para pescar e caçar.

6 Uma dança ritualística que consagra a união entre aqueles que dançam.

7 Língua materna dos Potiguara. 
A educação escolar indígena passou por diversas transformações ao longo dos tempos, sabemos que a escola possui um papel essencial para a formação de um povo e, nesse sentido, a construção de escolas nas aldeias tem a função de fortalecer a luta dos povos indígenas por uma educação escolar indígena de qualidade, pautada nos princípios de uma democracia participativa e comunitária, haja vista que outrora os estudantes residentes em aldeias enfrentavam inúmeras dificuldades ao precisar deslocar-se para a cidade em busca de uma instituição escolar. Atualmente, a população indígena Potiguara é de aproximadamente 19 mil habitantes, distribuídos nas cidades de Baía da Traição, Marcação e Rio Tinto, e se concentram no Litoral Norte paraibano, mais precisamente numa área situada entre os rios Camaratuba e Mamanguape.

Para este trabalho, foi feito o levantamento de todas as escolas localizadas em aldeias da cidade de Baía da Traição, assim, é possível notar o avanço na construção de instituições de ensino nessas aldeias, como demonstra a tabela a seguir:

Tabela 1 - Relação das unidades municipais e estaduais de ensino localizadas em aldeias de Baía da Traição.

\begin{tabular}{|c|c|c|c|}
\hline N. & Nome da escola & $\begin{array}{c}\text { Dependência } \\
\text { Administrativa }\end{array}$ & Localização \\
\hline 01 & EEIEFM Pedro Poti & Estadual & Aldeia São Francisco \\
\hline 02 & EMEF Centro Social São Miguel & Municipal & Aldeia São Francisco \\
\hline 03 & EEIEFM Akajutibiro & Estadual & Aldeia Akajutibiró \\
\hline 04 & EMEF Paulo Eufrásio Rodrigues & Municipal & Aldeia São Miguel \\
\hline 05 & EMEF Maria das Dores Borges & Municipal & Aldeia Galego \\
\hline 06 & EMEF Dr. Antônio Estigarribia & Municipal & Aldeia Forte \\
\hline 07 & EMEF Manoel Ferreira Padilha & Municipal & Aldeia Silva \\
\hline 08 & EMEF Celina Freire Rodrigues & Municipal & Aldeia Cumaru \\
\hline 09 & EMEF João Bezerra Falcão & Municipal & Aldeia Tracoeira \\
\hline 10 & EMEF Naíde Soares da Silva & Municipal & Aldeia Laranjeiras \\
\hline 11 & EMEF João Eugenio Barbosa & Municipal & Aldeia Santa Rita \\
\hline 11 & EMEF Cacique Manoel Santana & Municipal & Aldeia Bento \\
\hline 13 & EMEF Dr. Carlos Rodrigues & Municipal & Aldeia Lagoa do Mato \\
\hline
\end{tabular}

Fonte: Secretaria de Educação de Baía da Traição, 2017. 
Dentre essas escolas, apenas as duas estaduais ofertam a educação indígena diferenciada, o que é preocupante se analisarmos que todas estão inseridas em áreas indígenas, e mais inquietante é o que afirma Patrícya Silva (2010, p. 32).

[...] muitas escolas de aldeias indígenas têm sido, com raras exceções, réplicas das escolas das cidades configurando a mesma proposta de currículos, de critérios de avaliação, carga horária e estrutura de funcionamento.

Destarte, é nítido que a educação escolar indígena diferenciada ainda não tem recebido a atenção necessária, seja por parte dos governantes e educadores, ou pelas Políticas Públicas. É preciso compreender que esse modelo educacional possui uma função social de suma importância para as comunidades indígenas e a sociedade como um todo, que é contribuir para uma vida ressignificada, concedendo aos indígenas uma maneira de ensinar, ler, escrever e principalmente, contar sua própria história à sociedade não indígena, defendendo suas causas, seus direitos e, promovendo assim, a interculturalidade. As escolas que ofertam a educação indígena diferenciada possuem sua organização própria, levando em consideração a realidade de cada aldeia, é uma escola onde as decisões devem ser tomadas em conjunto, com a participação de todos, gestores, professores, funcionários, liderança local, pais e alunos. Quanto ao calendário escolar, também é diferenciado, sendo elaborado pelos próprios professores indígenas e adequado de acordo com o cotidiano dos alunos, respeitando as práticas culturais presentes, tais como festas comunitárias, rituais religiosos e datas comemorativas. A tabela abaixo demonstra o modo como é elaborado este calendário, utilizando como estudo de caso a E.E.I.E.F.M. Akajutibiró.

Tabela 2 - Calendário Escolar Específico

\begin{tabular}{|c|l|}
\hline \multicolumn{2}{|c|}{ Datas comemorativas } \\
\hline Março/abril & $\begin{array}{l}\text { Plantio de milho e feijão, Semana Santa, coleta de mangaba e } \\
\text { Páscoa; }\end{array}$ \\
\hline Abril & Semana de Conscientização Indígena; \\
\hline Maio & $\begin{array}{l}\text { Dia da Padroeira da Aldeia Akajutibiró (Nossa Sra. de Fátima), } \\
\text { Comemoração do Dia das Mães e aniversário da Aldeia } \\
\text { Akajutibiró (dia 31); }\end{array}$ \\
\hline Junho & Semana do Meio ambiente e Festas Juninas; \\
\hline Julho & Mostra de Ciências; \\
\hline Agosto & Dia dos Pais, Estudantes e Gincana Cultural; \\
\hline
\end{tabular}




\begin{tabular}{|c|l|}
\hline \multicolumn{2}{|c|}{ Datas comemorativas } \\
\hline Setembro & $\begin{array}{l}\text { Semana da Pátria, Jogos Escolares Indígenas e Novenário de } \\
\text { São Miguel; }\end{array}$ \\
\hline Outubro & Dia das Crianças, dos Professores e Funcionários; \\
\hline Novembro & Feira Cultural; \\
\hline Dezembro & $\begin{array}{l}\text { Aniversário da Escola, Formatura e Encerramento do Ano } \\
\text { Letivo. }\end{array}$ \\
\hline
\end{tabular}

Fonte: Projeto Político Pedagógico da E.E.I.E.F.M. Akajutibiró, 2017

No tocante às disciplinas ofertadas, o currículo não difere completamente das escolas não indígenas, no entanto a forma de abordagem das temáticas são distintas. Os professores têm o cuidado de sempre relacionar o tema abordado com a realidade dos alunos, levando-os a perceber que a disciplina tem relevância no seu cotidiano. Dentre as disciplinas que são acrescidas no currículo, estão: a língua tupi, música e etno-história, esta, por se tratar de uma disciplina específica, tem por finalidade repassar aos estudantes indígenas a importância do respeito e da valorização cultural de seu povo.

Esse ensino está embasado na contextualização de reafirmação étnica, priorizando o respeito das práticas culturais no tocante a língua materna, questão territorial, direitos e deveres existentes nas aldeias indígenas nacionais e locais, levando os estudantes a analisar, discutir e participar de maneira construtiva das decisões que envolvem aldeia e espaço escolar, possibilitando assim, a formação de cidadãos indígenas conscientes de seus direitos e deveres, que sentem orgulho de sua autoafirmação cultural como pertencente ao povo indígena.

\section{PROBLEMÁTICA MATERIAL}

Apesar de todo o esforço para fazer valer as leis que regem a educação escolar indígena diferenciada, o corpo escolar e os alunos esbarram em um problema reincidente, o livro didático. Historicamente, esse material oriundo da Europa, chegou ao Brasil no século XIX em forma de compêndios, trazendo consigo o propósito de sistematizar e controlar o ensino e a aprendizagem dos alunos aos moldes da educação francesa (MARIANO, 2017).

A partir de 1930, a quantidade de livros didáticos produzidos genuinamente no Brasil passava a crescer, e mesmo o modelo francês ainda sendo usado como 
referência, já era possível notar uma atualização no conteúdo desses livros, que passavam a conter mapas, documentos e ilustrações. É também na década de 1930 que esses manuais passaram a ser elaborados para os alunos, haja vista que só o corpo docente a eles tinha acesso. Assim, como afirma Bittencourt (1993, p. 109), "o livro didático tornou-se, rapidamente o texto impresso de maior circulação, atingindo uma população que se estendia por todo o país".

Na década de 1970, os livros didáticos apresentaram mais mudanças significativas no tocante ao conteúdo. Para além das ilustrações, mapas e documentos, possuíam então mais dois recursos facilitadores de ensino, os exercícios e os planejamentos, logo, tornou-se um material essencial para os professores. Esse novo processo favoreceu e muito as editoras, que aumentaram a clientela e passaram a produzir cada vez mais livros didáticos. Nesse contexto, o Programa Nacional do Livro Didático (PNLD) foi criado no ano de 1985, com o objetivo de auxiliar o trabalho pedagógico dos educadores, através da distribuição de livros didáticos para alunos e professores da educação básica.

A partir dos anos de 1990, diante da chamada Nova História, os livros didáticos passaram a abordar uma história cultural e social cada vez mais atual, introduzindo novas temáticas, tais como as narrativas de mulheres, trabalhadores, indígenas e negros, substituindo assim, a tradicional história política. No entanto é possível perceber que, mesmo com todas essas novas narrativas, como afirma Mariano (2017, p. 49), "[...] muitos livros didáticos de História do Brasil reproduzem posturas tradicionais, mantêm arraigados certos conteúdos e metodologias que prejudicam o processo de ensino-aprendizagem".

É nítido que, ao longo dos anos, o livro didático passou por diversas modificações no tocante a estrutura, linguagem e tamanho. Essas alterações também refletiram esteticamente, sendo notável a valorização da qualidade de imagens, mapas, desenhos, inclusive o tipo de papel.

Atualmente, para a produção desse material didático, é necessário o trabaIho de uma equipe formada por autores, editores, profissionais da iconografia e da arte, revisores, entre outros, contudo ainda é possível encontrar exemplares perpetuando uma historiografia eurocêntrica, na qual o indígena é representado como aquela figura cristalizada, mencionado sempre no passado como se não mais existisse. Quando são citados no presente, sempre é referindo-se aos indígenas 
do Estado do Amazonas, Mato Grosso ou de alguma aldeia isolada da civilização, deixando de mencionar que existem indígenas vivendo em sociedade, que estudam, trabalham e têm acesso a tecnologias como qualquer pessoa e, portanto, deveriam ser representados também dessa forma nesses materiais didáticos.

Um fato que chama a atenção é que os livros aprovados pelo PNLD para serem distribuídos nas escolas indígenas não difere em nada dos livros distribuídos nas escolas não indígenas, não existe uma editora específica na produção desses materiais, o que seria interessante por tratar-se de escolas indígenas de educação diferenciada. Diante do exposto, é notável a importância de analisar esses materiais que são distribuídos nessas escolas, a fim de perceber como esses povos estão sendo neles representados. Para tanto, temos como estudo de caso os materiais utilizados na Escola Estadual Indígena de Ensino Fundamental e Médio Akajutibiró. Iniciamos a análise pelos materiais adotados entre os anos 2014 e 2016; nesse caso, foram selecionados dois livros didáticos da coleção História nos dias de hoje, publicados pela editora Leya e utilizados no 6으 e 7으 ano.

É importante frisar que, apesar da análise em relação à apresentação e organização desses materiais, o foco deste trabalho é analisar a temática indígena e as representações desses povos nos livros didáticos.

Na apresentação do livro História nos dias de hoje (CAMPOS; CLARO; DOLHNIKOFF, 2012a), os autores tentam passar a ideia de que o estudo da história poderia se tornar mais interessante se associado a jogos de qualquer natureza, buscando-Ihes compreender o significado social, religioso, político e cultural ao longo do tempo e em diferentes formações sociais.

O primeiro a ser analisado foi o livro do 60 ano que é organizado em 10 capítulos, cada um contendo ferramentas que, segundo os autores, facilitará o estudo dos alunos, a exemplo da sessão "Por dentro do jogo", que é dividida em 9 subseções: Jogo aberto; Texto básico; Bate-bola; Olho no lance; Tá ligado?; Leitura complementar; Permanências e rupturas e por fim, Salto triplo. Segundo os autores, toda essa informação adicional irá contribuir para que os alunos possam aprofundar-se sobre os assuntos, e, como já era de se esperar, os conteúdos estão sempre fazendo menção a jogos, principalmente o de futebol (haja vista que um dos autores é pesquisador sobre futebol e assuntos lúdicos). O Passo a passo é uma outra sessão do livro, uma espécie de roteiro elaborado pelos autores para ajudar 
os alunos a analisar imagens, textos, dicas para uma boa leitura, leitura de mapas e pesquisa na internet; mais uma vez, os jogos são utilizados como referência na hora da explicação, e uma das dicas têm como modelo uma partida de futebol, outra, a cobrança de pênalti. É nítido que existe um excesso de informações, que, em muitos casos, ao invés de ajudar o aluno, acaba por deixá-lo mais confuso, o que é perigoso, pois pode atrapalhar o processo de ensino aprendizagem.

Nessa primeira parte do livro, já é possível notar que o material não condiz em nada com a realidade do público alvo alunos indígenas, afinal, em nenhum momento eles foram mencionados ou representados na apresentação, ou nas duas sessões que antecedem o sumário e o conteúdo.

No tocante ao conteúdo, o livro não fala especificamente dos povos indígenas do Brasil, muito menos da Paraíba, o que demonstra uma reprodução da postura tradicional, que de modo algum promove visibilidade aos povos indígenas, como determina a Lei. No capítulo dois, intitulado Pré-História e História, os autores abordam temas sobre arte rupestre, sítios arqueológicos, entre outras temáticas, no entanto os povos indígenas sequer são citados.

A sequência do conteúdo deixa nítido que, mesmo escrevendo nos anos 2000, os autores mantêm visões tradicionais, e isso se torna ainda mais evidente quando são abordados apenas os Sambaquis como os primeiros caçadores e coletores que habitaram o litoral brasileiro, e não evidenciam os povos indígenas no contexto geral da ocupação territorial do Brasil. No entanto os autores tiveram o cuidado de não se referir a esses caçadores e coletores como selvagens e sim "nossos antepassados". O capítulo segue abordando todos os assuntos da pré-história, porém, mais uma vez, os alunos indígenas, em momento algum, são representados, a única palavra que lhes é familiar encontra-se nesse trecho onde Campos, Claro, Dolhnikoff (2012b, p. 41) explicam: "[...] O nome tem origem tupi e quer dizer justamente monte de marisco (do tupi tamba'ki= monte de conchas)".

A proposta do livro é interessante para os alunos, porém ainda não consegue atender as necessidades do público-alvo, pois continua propagando uma educação em que os povos indígenas não são representados.

Seguindo a análise, partiremos para o livro do 7ㅇ ano, cuja apresentação e organização é similar ao livro anterior, apenas o número de capítulos difere, pois este possui 15. No tocante ao conteúdo, os autores abordam a questão indígena 
no capítulo dez. Partindo do título O Brasil antes de Cabral, já se nota uma diferença em relação ao livro do 60 ano, dando a entender que vai se tratar de Brasil e da questão indígena. Os autores iniciam o conteúdo falando sobre os primeiros habitantes do Brasil, da diversidade linguística e cultural existente entre esses povos em 1500, explicam que, para além dos quatro principais grupos indígenas (Tupi, Aruak, Karib e Jê), havia outros menores, tudo de maneira clara e de fácil compreensão aos alunos, porém os autores Campos, Claro, Dolhnikoff (2012b, p. 178-9) falham ao usar os termos no passado na maioria de suas falas, como nesse trecho em que afirmam que os indígenas: "[...] Viviam da pesca, da caça e da coleta de frutos e raízes. [...] também praticavam a agricultura. Plantavam mandioca, milho e batata doce".

O conteúdo do livro é relevante, no entanto é necessário fazer uma conexão entre passado e presente, mostrando aos alunos que essa realidade ainda existe, que ocorreram mudanças no cotidiano desses povos sim, no entanto eles continuam mantendo vivas suas tradições e culturas, apesar de tantos anos de contato com os não indígenas. Neste outro trecho fica nítida a figura do indígena representada como pertencente ao passado, quando os autores Campos, Claro, Dolhnikoff (2012b, p. 184) relatam que: "A mandioca era um dos principais alimentos para os indígenas. Dela faziam farinha, bebidas, caldo e mingau" (grifo nosso).

No decorrer do texto, não há o cuidado de explicar que os indígenas continuam suas práticas, isso até hoje, que não deixaram de plantar e utilizar a mandioca em seu cotidiano. Ao ler esse trecho, o aluno indígena, automaticamente, vai reconhecer esses hábitos que são comuns à sua realidade, em especial aquele que vive em uma aldeia, no entanto ele não vai compreender o fato de o seu cotidiano está sendo posto no livro didático como algo do passado, como se isso não fizesse mais parte da sua realidade.

Em relação ao cotidiano, pela primeira vez os autores usam o tempo presente, quando afirmam que em algumas aldeias ainda se praticam rituais e danças, no entanto, no decorrer do texto, retornam a mencioná-los no passado, quando falam apenas de como era a educação indígena, que não havia escolas ou professores, esquecendo de salientar que, desde 1988, essa educação vem sofrendo mudanças e que os indígenas já possuem todo acesso à educação como qualquer pessoa, 
com escolas dentro de suas comunidades, com sistema e métodos específicos e diferenciados, tendo acesso às mesmas tecnologias disponíveis aos não indígenas.

Algo que chama a atenção, na página 190 do livro, é a fotografia de um líder indígena do povo Suruí, chamado Almir Narayamoga, na qual este se encontra no meio da floresta sentado em um tronco de árvore, vestindo uma bermuda, pintado e adornado, segurando nas mãos um notebook. A foto foi tirada em 2011 e fala a respeito de um site do povo indígena Suruí, criado em 2007. O site é fruto de uma parceria do então líder Almir com uma empresa estadunidense, para que seu povo pudesse fazer o controle de suas terras e, assim, combater crimes ambientais.

Informações como estas, que levam o aluno indígena a se reconhecer na história que está sendo contada, deveriam estar presentes em todo o conteúdo, mostrando como viveram e como vivem, passado e presente caminhando lado a lado. No capítulo 11, os autores vão falar sobre a conquista colonial portuguesa e, mais uma vez, prevalece a história que foi, ou seja, apresentando um passado que não conversa com o presente.

Um outro material analisado foram dois livros didáticos da coleção História: Sociedade e cidadania, publicados pela editora FTD, a serem adotados entre os anos 2017 e 2019, nas turmas do 6으 e 7ㅇano.

Na apresentação do livro História: Sociedade e cidadania (BOULOS JÚNIOR, 2015a; 2015b), o autor dialoga com aluno que irá utilizar o livro, explicando o processo de produção desse material até chegar às suas mãos. Nesse contexto, apresenta um pouco sobre o papel de cada profissional do mundo do livro, fazendo um agradecimento a todos eles pela produção da coleção. O autor e sua equipe propõem a confecção de um blog feito pelos alunos com o auxílio do professor; para tanto, estabelecem algumas regras para pôr a ideia em prática. Todavia isso é uma sugestão do autor que funcionaria como mais um facilitador pedagógico ao professor, ficando a critério deste utilizá-la.

O primeiro livro analisado foi o do $6^{\circ}$ ano, que, por sinal, já chama atenção desde a capa, trazendo a fotografia de uma criança indígena trajando adornos e com a pele pintada, como demonstra a imagem a seguir. 
Figura 1 - Capa do livro História: sociedade e cidadania

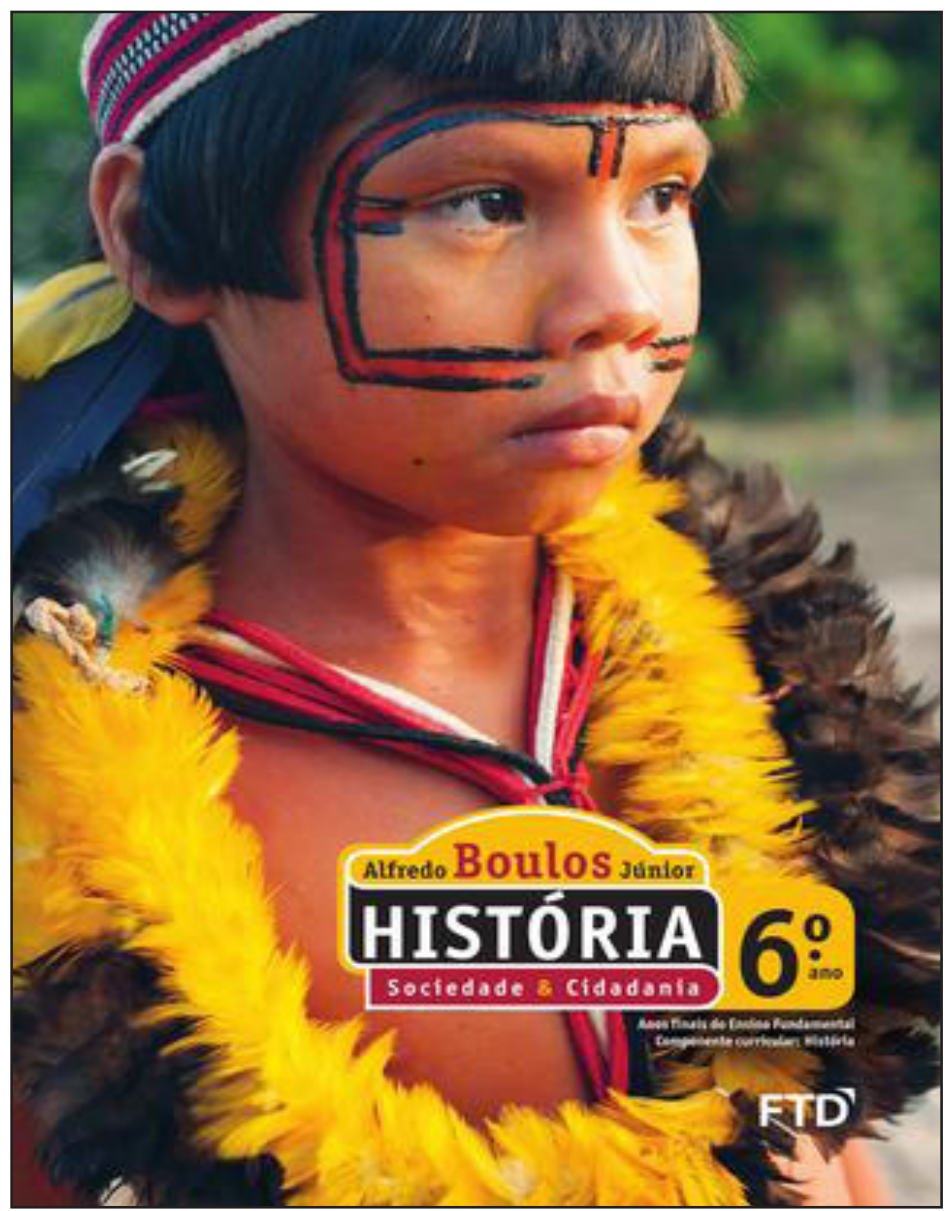

Fonte: Boulos Júnior e Alfredo (2015a).

O livro está organizado em 4 unidades, divididas em 14 capítulos. Cada unidade se constitui de ferramentas que são facilitadores de compreensão para os alunos e recebem os seguintes títulos: Abertura de unidade, Abertura de capítulo, Dialogando, Para refletir, Para saber mais e Atividades, que se divide em três fases: I- Retomando, II- Leitura de imagem, Leitura e escrita de textos, Cruzando fontes, Integrando com... (nesta seção o autor faz a interação da disciplina de História com outras disciplinas), III - Você cidadão. Esses facilitadores estão distribuídos ao longo dos textos, agregando conhecimento, e por ser de fácil compreensão, não se torna um excesso de informações. 
Só de olhar a capa desse livro, o aluno indígena já se sente representado, além de subentender que o conteúdo trará algo relevante sobre sua história, como de fato traz. As duas primeiras unidades que totalizam cinco capítulos, estão representando esses povos de alguma maneira, seja através de fotos, textos ou ilustrações. No tocante ao conteúdo, a primeira unidade intitulada História, cultura e patrimônio traz diversas fotografias e ilustrações dos indígenas, representados de diferentes formas, no cotidiano, nas brincadeiras, na singularidade do seu calendário, nos bens culturais e nos hábitos, tudo seguido de um contexto relevante.

A unidade dois intitulada O legado dos nossos antepassados traz no capítulo quatro A "pré-história" brasileira, título bem sugestivo por sinal. Nesse capítulo, o autor fala sobre os povos dos sambaquis, relata quem eram, como viviam, o que comiam, as características físicas, a questão dos funerais, tudo de maneira leve e clara, mas o que mais chama atenção é o trecho em que Boulos Júnior (2015a, p. 83) cita os povos tupis: "Há cerca de 2 mil anos os povos dos sambaquis despareceram, provavelmente porque foram vencidos pelos grupos tupis, que na época se expandiam pelo litoral".

No subtítulo Agricultores e ceramistas da Amazônia, o autor fala sobre a prática da agricultura dos povos dessa região, da produção de alimentos e de como eles aprenderam a transformar uma planta venenosa como a mandioca em alimentos como: o beiju, a tapioca e a farinha de mandioca. No decorrer do texto, o autor relata que, além da agricultura, os povos amazônicos também desenvolveram a produção ceramista de diversos tipos, produzidas através do cozimento da argila em forno, sendo que a mais importante desse gênero foi a cultura marajoara.

No capítulo cinco, intitulado Os indígenas: diferenças e semelhanças, o autor inicia com fotos de dois cocares representando duas etnias distintas, os Yawalapiti e os Bororo, ambas localizadas no Estado do Mato Grosso, cujas fotografias pertencem ao acervo memorial da América Latina, São Paulo, 2008, e são utilizadas como reflexão acerca das diferenças existentes entre os povos indígenas. No subtítulo Povos indígenas na América, o autor recorda a chegada de Colombo à América, que era habitada por 57,3 milhões de indígenas e milhares de povos. A questão da generalização dos povos indígenas fica bem clara nas palavras de Boulos Júnior (2015b, p. 95) 
Sabemos que a palavra "índio" nasceu de um erro histórico [...] Hoje em dia, muitas pessoas continuam vendo os índios como se fossem todos iguais. Ocorre, porém, que o "índio" genérico não existe. Existem os tupiniquins, os caetés, os caiapós, os yanomamis e muitos outros. Cada grupo se vê como um todo e diferente de outros grupos.

No subtítulo Povos indígenas no Brasil, recorda-se a chegada dos portugueses às terras brasileiras e o autor faz um comparativo do número de povos indígenas que aqui viviam em relação aos dias atuais. O texto é composto por duas figuras de indígenas: a primeira representa aqueles que vivem em aldeias; a segunda, os que vivem em cidades. O autor recorda que, além desses grupos, existem 53 povos indígenas ainda vivendo isolados na floresta. Na sessão Dialogando, o aluno é provocado a pensar se o modo de vida dos indígenas continua exatamente igual ao passado.

Em Conhecendo os povos indígenas, o autor esclarece que cada etnia possui uma subjetividade no tocante à língua, crenças e principalmente na organização social, Boulus enfatiza que nossos hábitos são reflexos da cultura indígena, no entanto reconhece que ainda se sabe pouco sobre sua real contribuição para a história e a cultura brasileiras.

No decorrer do texto, o autor fala sobre as diferenças entre esses povos, podendo ser notadas através das línguas, dos traços físicos e dos adornos; para representá-las, o autor utiliza duas fotos de indígenas da atualidade, pertencentes às etnias Yanomami (AM) e Paresi (MT), com isso, estimula os alunos a perceber visualmente essa distinção observando detalhes como o desenho do rosto, os adereços utilizados e a pintura corporal. A legenda é composta por informações básicas sobre as imagens como: as fontes, etnias, o ano e a localização em que as fotos foram produzidas.

No subtítulo As semelhanças entre os indígenas, o autor esclarece ao longo do texto que os povos indígenas possuem diferenças e semelhanças, como por exemplo, a visão sobre a posse da terra que, para eles, deve pertencer a quem trabalha nela, bem como a divisão do trabalho que é realizada por sexo e idade.

Outro tema abordado é a questão da infância, adolescência e vida adulta dos indígenas, em que o autor relata algumas brincadeiras das crianças, como brincar no mato subindo em árvores e nadar nos rios; Boulos explica que as crianças também ajudam nas tarefas da aldeia conforme sua força e capacidade. 
No tocante à adolescência, é relatado apenas o que ocorre com os rapazes em algumas etnias; para tanto, o autor utiliza como exemplo a aldeia xavante, na qual os rapazes são isolados por um período de cinco anos, sendo submetidos a provas de coragem e resistência, entre outros rituais. A vida adulta é basicamente resumida em constituir família, prover o sustento do grupo e participar ativamente da vida social, obtendo cargos e funções especiais ligadas aos rituais, como puxar os cantos, que é função do cantador, tocar algum instrumento e ser mestre de cerimônia, cuja função é de representar um determinado personagem numa cerimônia.

É nítido que esse livro didático traz uma visão bem diferente dos anteriores, dando mais visibilidade aos povos indígenas. No entanto há muito ainda que se acrescentar, como por exemplo, os povos indígenas do Nordeste, haja vista que esse material também é distribuído em escolas indígenas dessa região, entretanto o autor está sempre se referindo aos povos do Estado do Amazonas (AM) e Mato Grosso (MT), o que reforça a ideia de que só existem indígenas nessas regiões, o que, obviamente, não condiz com a realidade.

Seguindo a análise, partiremos para o livro do 7ํ ano, cuja apresentação e organização é similar ao livro anterior, bem como o número de unidades e capítulos. No tocante ao conteúdo, o autor aborda a questão indígena na Unidade três, intitulada A formação do Estado Moderno, que traz o capítulo onze América: astecas, maias, incas e tupis. Este se inicia com três fotografias de indígenas pertencentes a distintas etnias, provocando o aluno a perceber as semelhanças e diferenças entre eles. Ao longo do texto, o autor faz um link entre o assunto que está sendo trabalhado e o que foi visto no livro do 6 o ano, referindo-se à chegada de Colombo à América.

No decorrer do texto, é feita uma minuciosa abordagem sobre as diversas fontes utilizadas para se estudar os povos indígenas da América, como por exemplo as fontes materiais, escritas e visuais.

No tocante aos tupis, o autor aborda a questão do número de indígenas que habitavam o litoral brasileiro no período da chegada de Cabral, bem como a organização de suas aldeias. O texto é ilustrado com a fotografia de uma criança tupi num dia de lazer, tomando banho de rio. Um outro fato abordado é a questão da organização de suas moradias que, no século XVI, eram formadas por 4 a 8 casas 
que os tupis chamavam de malocas. O convívio familiar também foi detalhado nesse contexto, o autor relata como se organiza a família extensa ${ }^{8}$.

A maior parte do conteúdo sobre os tupis está se referindo aos indígenas apenas no passado, sem fazer menção ao modo de vida desses povos na atualidade, o que fica evidente nas várias ilustrações do século XVI que compõem o texto, como por exemplo, a utilização do detalhe de um atlas de 1542, do francês Jean Rotz, no qual é representado o cotidiano desses povos, mostrando os detalhes da organização das malocas, como funcionava o escambo do pau-brasil e até o conflito entre os grupos indígenas, o que era comum nesse período.

Figura 2 - Atlas de Jean Rotz, 1542

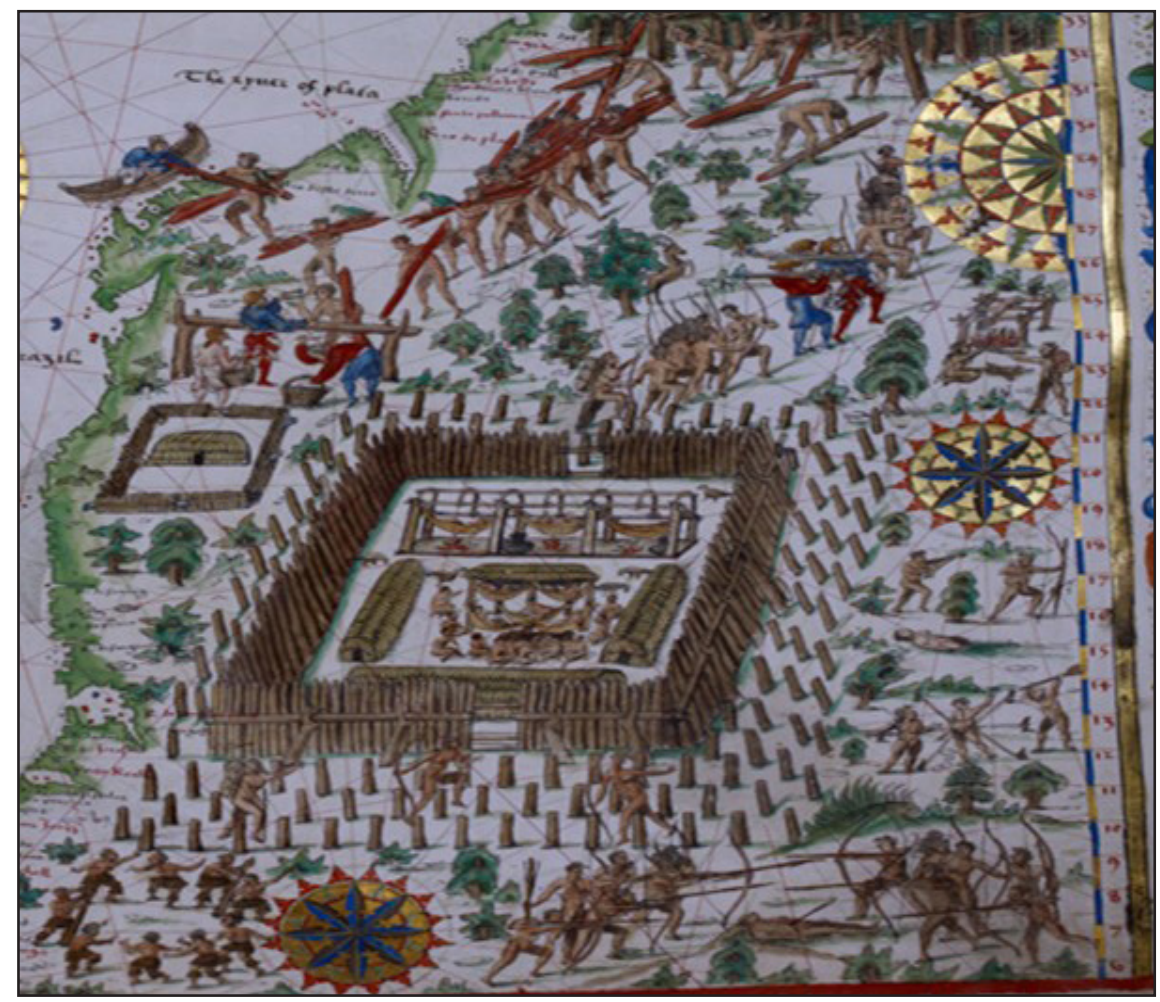

Fonte: Boulos Júnior e Alfredo (2015b).

\footnotetext{
8 Família constituída não apenas por pai, mãe e filhos, mas também por avós, avôs, primos, sobrinhos e outros parentes.
} 
$\mathrm{Na}$ legenda, o autor explica o contexto da imagem e cada detalhe nela representado, Boulos enfatiza principalmente a organização das malocas.

No decorrer do texto, é feita uma abordagem acerca da forma do governo dos tupis, na qual fica claro que eles possuíam um modo próprio de regular as aldeias, que consiste na divisão do poder entre eles. No entanto cada aldeia possuía um líder chamado pelos tupis de morubixaba, e este não possuía regalia alguma. Boulos Júnior (2015b, p. 240) explica que havia um processo para se tornar líder "[...] era necessário reunir em torno de si muitos parentes e guerreiros; ser valente, conhecer os costumes de seu povo e falar bem em público".

Assim como o líder, havia uma outra figura de grande importância entre os tupis, que era o líder religioso, denominado pajé ou caraíba. A imagem que representa um morubixaba é a xilogravura presente na obra do viajante francês André Thévet, cuja representação do líder se assemelha mais a um europeu do que propriamente um tupi (Figura 3). O autor utiliza a gravura de Theodore de Bry para representar um ritual de cura organizado pelos pajés Tupinambás (Figura 4). Nessas duas passagens do texto, vemos o indígena representado no passado; em momento algum, o autor menciona que essas figuras tão importantes para esses povos continuam existindo e exercendo um papel fundamental para a organização das aldeias. 
Figura 3 - Xilogavura, André Thévet, 1550

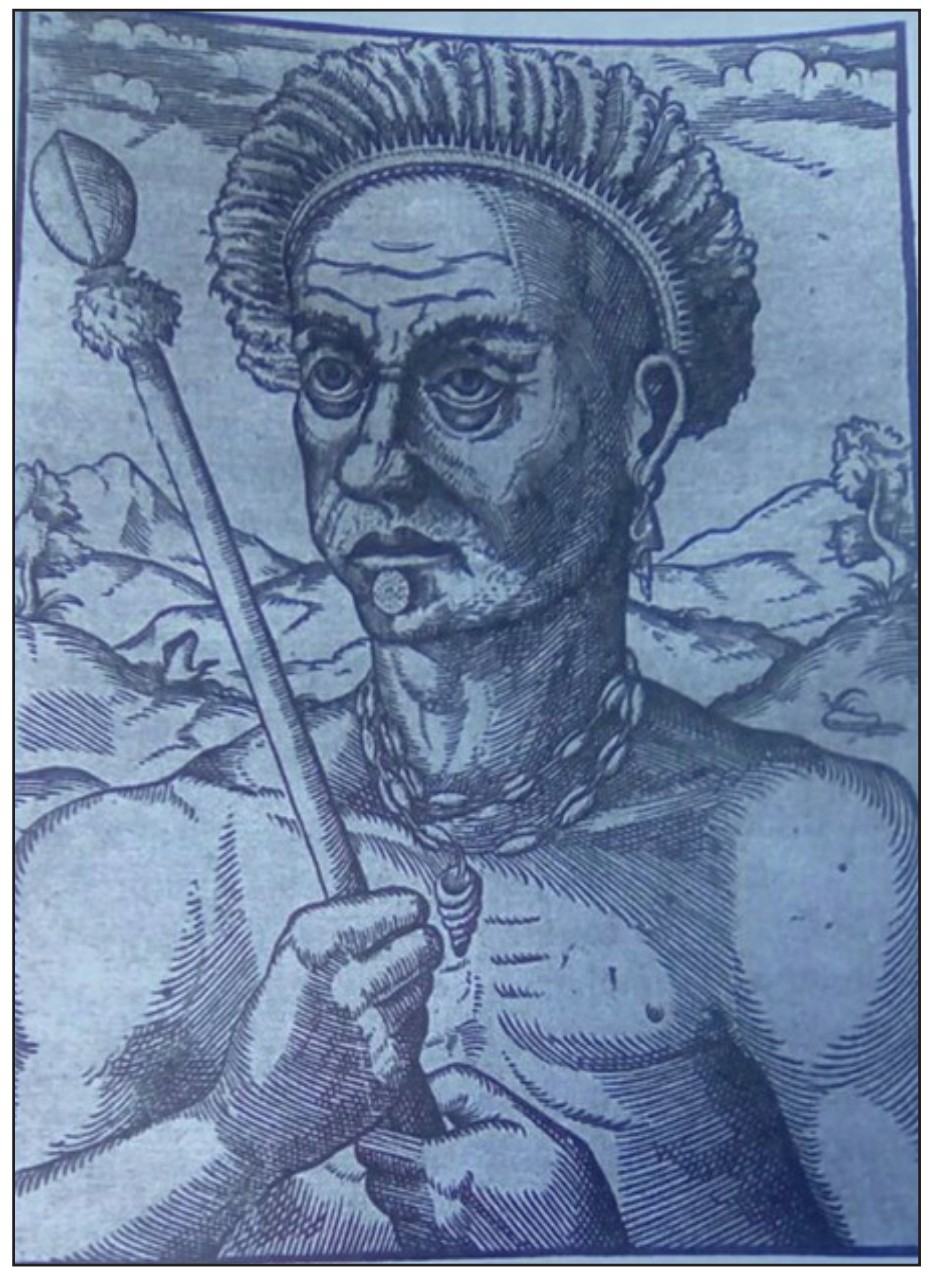

Fonte: Boulos Júnior e Alfredo (2015b). 
Figura 4 - Pajés tupinambás. Theodore de Bry, 1550

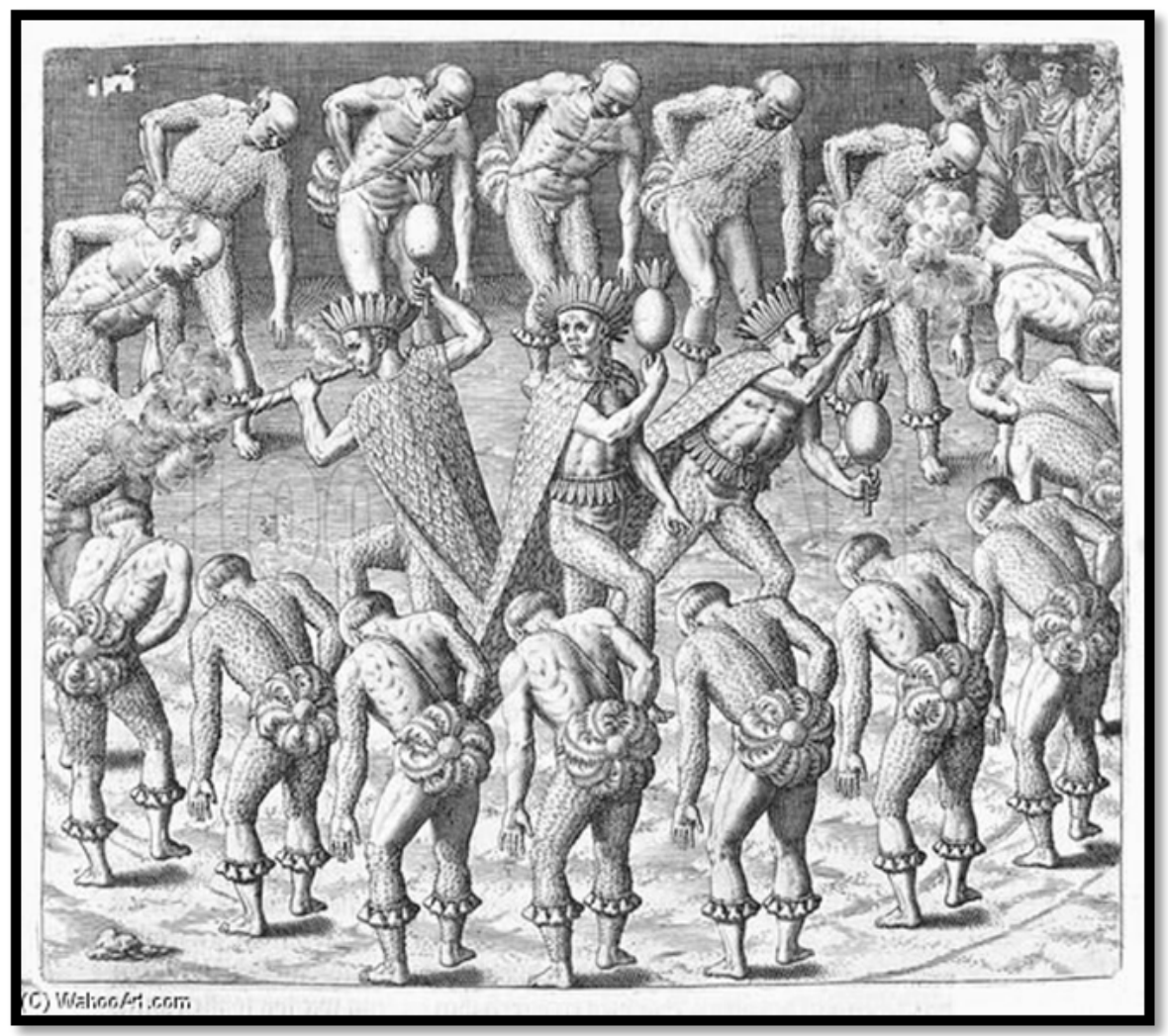

Fonte: Boulos Júnior e Alfredo (2015b).

No subtítulo Indígenas do Brasil e suas contribuições, o autor fala sobre as plantas alimentícias e medicinais que foram descobertas e domesticadas pelos ameríndios. O texto é ilustrado pelas imagens de alguns desses alimentos, como batata-doce, mandioca, milho entre outros. Na sessão para saber mais, é relatado o processamento da mandioca em texto e em fotos; a primeira imagem mostra como a mandioca é espremida até se tornar farinha, na segunda imagem, são retratadas mulheres indígenas preparando o beiju.

A unidade quatro, intitulada Nós e os outros, traz no capítulo treze, Colonização portuguesa: administração, o relato de como se deu a colonização, descrevendo as expedições, o comércio do pau-brasil e a construção de feitorias para armazenar e comercializar essa madeira. Nesse capítulo, também é descrita 
a reciprocidade do estranhamento entre indígenas e portugueses no primeiro contato, bem como a chegada dos franceses e as alianças entre indígenas e colonizadores; outro tema abordado nesse contexto foi o confronto entre Portugal e França pelas terras brasileiras.

No subtítulo As capitanias hereditárias, o autor explica como funcionou essa administração das terras coloniais, enfatizando que fatores como a resistência de indígenas à ocupação de suas terras contribuíram para a falta de êxito desse sistema. Nesse contexto, finalmente Boulus Júnior (2015b, p. 279) cita a região nordeste mesmo que de maneira rápida no trecho "poucas capitanias tiveram o sucesso esperado, com exceção de Pernambuco, Bahia e São Vicente".

Uma outra questão abordada no decorrer do texto é a intervenção conjunta do governo e da igreja na colônia. No subtítulo A expansão do catolicismo e a ação dos missionários, o autor descreve a intervenção das ordens religiosas no Brasil a exemplo dos jesuítas, franciscanos, carmelitas, capuchinhos e oratorianos, à formação e à catequização dos povos indígenas.

Comparado ao livro anterior, é possível notar que esse material também concede uma boa visibilidade aos povos indígenas, porém é necessário o acréscimo da região Nordeste.

Fazendo um balanço entre os quatro materiais analisados, chegamos à conclusão de que os povos indígenas ainda são pouco conhecidos e estudados e que a visão que se tem desses povos continua, de certa forma, genérica.

É nítido que os dois últimos materiais dedicaram um pouco mais de espaço para discutir sobre os povos indígenas, principalmente no livro do $6^{\circ}$ ano, no entanto ainda há muito o que acrescentar, afinal, a ideia que se tem ao analisar esses materiais é a de que só existe indígena nos estados do Amazonas e Mato Grosso, haja vista que são os únicos a ter a imagem representada.

Levando em consideração o fato de os autores serem de São Paulo, o que, na maioria das vezes, pressupõe o desconhecimento da existência de indígenas no Nordeste, é preciso pensar numa maneira de solucionar esse problema, e uma boa alternativa seria que eles se dispusessem a rever seus conhecimentos sobre esses povos, levando em consideração que o seu material será distribuído em escolas indígenas de diversos Estados e todos esses povos precisam se 
sentir representados. Assim, seria interessante a participação desses autores em seminários que abordem a questão indígena de uma forma mais ampla.

Uma saída que as escolas indígenas Potiguara adotaram para contrapor a visão estabelecida nos livros didáticos é a confecção e utilização de materiais paradidáticos nas escolas. Esses materiais estão na forma de livros e cartilhas e propiciam visibilidade aos povos indígenas da Paraíba, para tanto, é preciso que os autores desses materiais tenham uma vivencia com os indígenas, para que os textos sejam elaborados de forma coletiva e direta com esses povos. Em sua maioria, esses autores são professores indígenas e integrantes de grupos de apoio a essas populações, cujas obras são elaboradas com a participação de integrantes da comunidade, através de relatos sobre sua história e seu cotidiano, em que abordam a cultura, a língua e a realidade dos povos indígenas na atualidade.

\section{CONSIDERAÇÕES FINAIS}

Realizar esse trabalho nas escolas da Baía da Traição representou para nós muito mais que uma simples coleta de dados, ele nos mostrou uma realidade da vivência escolar que, em geral, é totalmente ignorada pelo Estado e pela população não indígena.

Ao analisarmos esses materiais, conseguimos mensurar quão pouco conhecidos e estudados pelos profissionais do meio editorial são os indígenas, e isso é preocupante, afinal, esses autores estão escrevendo em um período atual em que as discussões sobre essa temática já avançaram tanto, que é inconcebível tamanho retrocesso como exposto.

Por outro lado, algumas editoras possuem uma abordagem mais abrangente desses povos, trazendo inclusive uma iconografia atual; outro ponto relevante é que os textos sempre aproximam passado e presente facilitando a compreensão e o autorreconhecimento do indígena enquanto agente atuante na história do Brasil, no entanto ainda há muito o que se acrescentar, muitas etnias precisam ser representadas.

Os livros didáticos são instrumentos essenciais no cotidiano escolar, auxiliando alunos e professores durante toda a trajetória do Ensino Básico e, por essa razão, fazem-se urgentes novas perspectivas historiográficas presentes em seu contexto. 
Destarte, não é pretensão deste trabalho apontar regras sobre como deve ser o livro didático ideal para ser distribuído nas escolas indígenas, mas apontar caminhos para a confecção de materiais didáticos que possibilitem uma maior visibilidade aos povos indígenas, e não apenas pela sociedade não indígena, mas para que eles se sintam verdadeiramente representados nas leituras e iconografias que compõem um livro didático. Para tanto, se faz necessária a participação de profissionais do meio editorial que possuam uma vivência com esses povos, que sejam atuantes em congressos sobre a educação escolar indígena, em que se reúnem diversos povos de todo o país. Com essa visão ampla da diversidade dos povos indígenas, talvez não tenhamos o livro didático perfeito, mas certamente esses alunos não precisariam se ver representados de forma tão genérica e até preconceituosa em seu material didático, e o papel desses povos na historiografia brasileira poderia ser de fato reescrito, libertando a cultura escolar dessa visão eurocêntrica que insiste em permear o imaginário didático nesses quase dois séculos de ensino de História do Brasil. Estas não são soluções mágicas para resolver o problema da falta de visibilidade dos indígenas nos livros didáticos, mas almeja-se fomentar futuros debates construtivos acerca da questão da representatividade das etnias nos materiais didáticos.

\section{REFERÊNCIAS}

AMOROSO, Marta Rosa. A mudança de hábito: catequese e educação para índios nos aldeamentos capuchinhos. In: SILVA, Aracy Lopes da; FERREIRA, Mariana Kawall Leal (Org.). Antropologia, história e educação: a questão indígena e a escola. 2. ed. São Paulo: Global, 2001.

BITTENCOURT, Circe Maria Fernandes. Livro didático e conhecimento histórico: uma história do saber escolar. Tese (Doutorado em História) - Universidade de São Paulo, São Paulo, 1993.

BOULOS JÚNIOR, Alfredo. História: sociedade e cidadania. Edição do aluno - 6o Ano. 3. ed. São Paulo: FTD, 2015a.

BOULOS JÚNIOR, Alfredo. História: sociedade e cidadania. Edição do aluno - 7o Ano. 3. ed. São Paulo: FTD, 2015b. 
BRASIL. Constituição Federativa do Brasil. Lei n. 11.645, de 10 março de 2008. Disponível em: http://www.planalto.gov.br/ccivil_03/_ato2007-2010/2008/lei/l11645.htm. Acesso em: 7 ago. 2017.

BRASIL. Constituição Federativa do Brasil. Lei n. 9.394, de 20 de dezembro de 1996. Disponível em: http://www.planalto.gov.br/ccivil_03/leis/L9394.htm. Acesso em: 7 ago. 2017.

BRASIL. Ministério da Educação. Programa Nacional do Livro Didático - PNLD. [S.d.]. Disponível em: http://portal.mec.gov.br. Acesso em: 12 out. 2017.

CAMPOS, F.; CLARO, Regina; DOLHNIKOFF, M. História nos dias de hoje. Edição do aluno - 6 Ano. 1. ed. São Paulo: LEYA, 2012a.

CAMPOS, F.; CLARO, Regina; DOLHNIKOFF, M. História nos dias de hoje. Edição do aluno - 70 Ano. 1. ed. São Paulo: LEYA, 2012b.

ESCOLA ESTADUAL INDÍGENA de Ensino Fundamental e Médio Akajutibiró. Projeto Político Pedagógico (PPP). Baía da Traição, Akajutibiró, 2017.

MARIANO, Nayana Rodrigues Cordeiro. A representação sobre os índios nos livros didáticos de história do Brasil. João Pessoa: Ideia, 2017.

PADILHA, Cristiane Ferreira. Educação escolar indígena: versão diversificada dos potiguaras. 2009. Trabalho de Conclusão de Curso (Especialização em História)- Universidade Estadual da Paraíba, Guarabira, PB, 2009.

BAÍA DA TRAIÇÃO (Cidade). Secretaria Municipal de Educação de Baía da Traição, [s.d.]. disponível em: https://www.baiadatraicao.pb.gov.br/portal/secretarias. Acesso em: 19 out. 2017.

SILVA, Patrícya Karla Ferreira. Educação escolar indígena: uma análise a partir da perspectiva da sexualidade e gênero no município indígena de Baía da Traição/PB. 2010. 88 f. Dissertação (Mestrado em Serviço Social) - Universidade Federal da Paraíba, João Pessoa, PB, 2010.

\section{Sobre as autoras:}

Simone Maria Silva: Indígena da Baía da Traição, Paraíba. Graduada em História pela Universidade Federal da Paraíba (UFPB). Membro efetivo do Abaiara- Grupos de Estudos Indígenas da Paraíba. E-mail: simoneamadeus@gmail.com 
Claudia Cristina do Lago Borges: Doutora em História. Professora Associada do Departamento de História da Universidade Federal da Paraíba (UFPB). Atua na área de História Indígena e Brasil Colonial. Coordena o Abaiara- Grupo de Estudos Indígenas da Paraíba. E-mail: claudialago.rn@gmail.com

Recebido em: 14 setembro 2018

Aceito em: 20 de fevereiro de 2019 
